\title{
ACCOMMODATION OF STRUCTURAL MOVEMENT IN GLASS-ALUMINIUM CURTAIN WALLS.
}

\author{
M.Sc.Eng. Stefan Trifonov; Prof. Dr. Dimitar Dakov \\ ${ }^{1}$ University of Architecture, Civil Engineering and Geodesy, 1 Hristo Smirnenski Blv., Sofia, Bulgaria \\ ABSTRACT
}

The problems of the structural movements of buildings and their effects on the building envelopes are discussed in this paper. The widely used methodology for assessing the capacity of curtain wall systems to accommodate different modes of building movement is explained and discussed. It is identified how generic types of structural movement such as live load deflection of floor structures and wind and earthquake induced building sway act on different types of glass-aluminium curtain wall systems. As there is a considerable lack of understanding between the disciplines as to which actual types and stages of building displacements should be considered, a universal analysis approach is proposed. Guidance for special considerations is provided. Special attention is paid to the considerable deviation between the theoretical approach for analysis and the actual behaviour of structures and enclosures observed in praxis, the former being in most cases very conservative.

Key words: glass, aluminium, curtain walls, façade engineering

\section{INTRODUCTION}

Accommodation of structural movement in glass envelopes has become one of the key issues of façade design in the last several years, due to the development of ever slimmer frames and ever growing glass formats. These factors in addition to the increasing flexibility of primary structures and their growing spans and floor heights mean in simple terms that structural members in buildings are subject to ever greater displacements while the ability of the glass enclosures to accommodate those is becoming more limited.

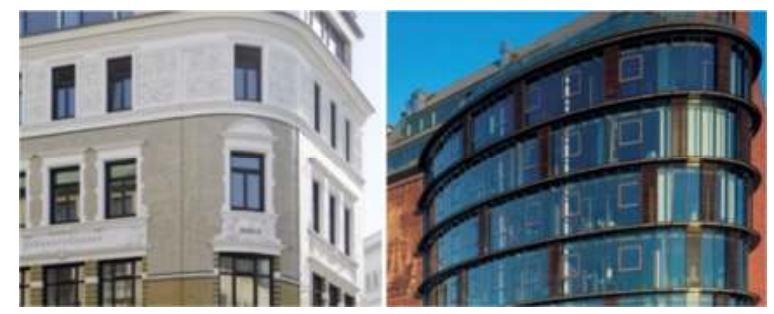

Fig. 1: Evolution of glass enclosures (left- traditional punched windows in massive external walls, rightglass- aluminium curtain wall, [1].

The problem is aggravated by the insufficient understanding of the matter.

The European curtain walling product standard EN 13830:2003 [2] requires that the design of curtain walling shall accommodate thermal and specified building movement without damage to components or deterioration of performance. It is however unclear how this could be achieved or how building movements shall be specified. Moreover the Eurocodes do not generally call for a full movement information to be provided, nor recommends allowable displacements for glazed buildings.

As a result of these circumstances, the design of glass envelopes for building movement is often accompanied by confusion and misunderstanding between the parties. 
Having identified the importance of this underdeveloped topic, this paper aims to improve the understanding of the matter and provide a common ground for discussion between the different parties involved in the building design.

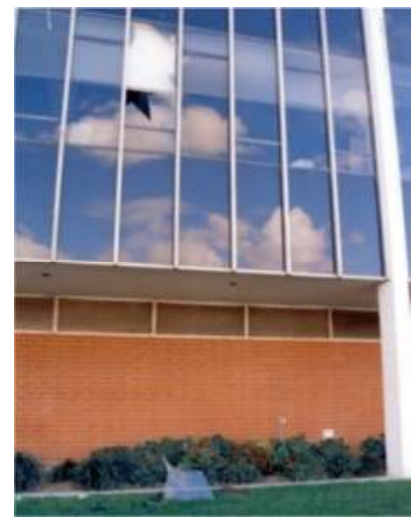

Fig. 2: Large shard of fallen glass, caused by seismic building movement [3].

\section{OVERVIEW OF AVAILABLE CODES AND LITERATURE}

In Europe three technical notes published by CWCT, [4], [5], [6] are used as a basis for analysis of the movement regime of glass-aluminium facades. The methodology proposed in these sources is largely based on accommodation of the movement in the edge clearance of the system without glass to frame contact (Figure 3).

[5] gives basic provisions for determining horizontal and vertical racking capacities of stick and unitized glass facades. The additional movement capacity provided by the rotation of the glass pane after contact has been referred to with brief explanation and noting that this additional capacity is usually not considered in favour of safety.

The American Architectural Manufacturing Association has published two test methods for evaluating curtain walls and storefronts subject to interstorey drift: AAMA 501.4-09 for static testing of wind and seismic sway, and AAMA 501.6-09 provides for dynamic testing, [7] and [8]. Both are very onerous, recommending testing drift of $\mathrm{H} / 100$ according to [7] (design drift typically limited to $\mathrm{H} / 300$ in Europe). The recommended pass/fail criteria are set in accordance to the building occupancy types.

After reviewing the façade systems, which have passed onerous testing according to [7] and [8], it easily becomes clear that there is a deviation between the widely used in Europe analytic approach and the movement capacities achievable in tests, the former being conservative.

The post-contact behavior of racking façade panes in seismic scenarios has been studied by Behr, [9] and [10], on a limited scale.

A static FEM analysis simulating earthquake drifts of glass curtain walls has been studied in [11].

Assessing the movement capacity of facades requires comprehensive information about the movements of the main structure. The Eurocodes however do not specifically refer to glazed buildings and do not recommend allowable displacements for such. [12] for instance recommends a too generic total allowable deflection of slabs of L/250 (e.g. $24 \mathrm{~mm}$ over a typical slab span of $6000 \mathrm{~mm}$ ) which is in many cases too liberal. To make matters more complicated [12] permits designers of reinforced concrete structures to omit completely the calculations of vertical deflections if certain span to depth ratios are maintained. This usually makes structural engineers reluctant to undertake complicated and time consuming analysis to determine the movements from all individual load cases. As a result façade 
designers often try to design the envelope to unrealistic or sometimes incorrect figures of structural movement.

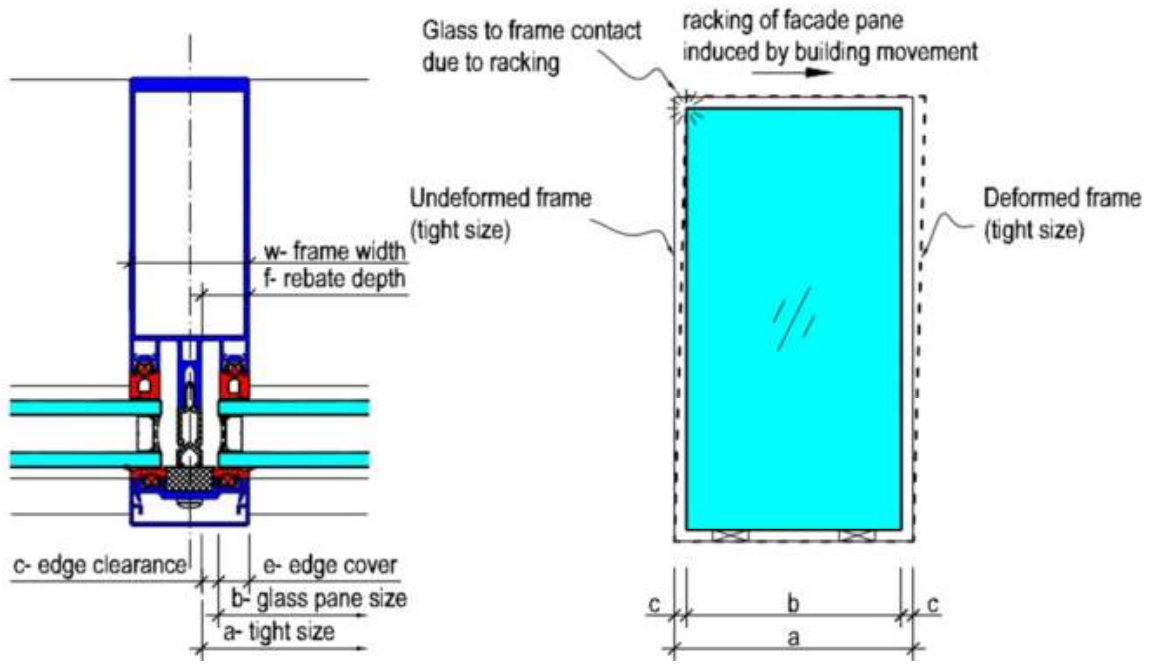

Fig. 3: Illustration of the edge clearance movement accommodation principle in dry glazed stick curtain walls (in accordance with [4], [5].

\section{TYPES OF BUILDING MOVEMENT AFFECTING THE INTEGRITY OF THE BUILDING ENVELOPE}

The typical stages of application of loads on a building structure are shown in Figure 4.

As it is evident providing values of accumulated displacements is insufficient for the purposes of façade design as designing the enclosure to such figures often leads to unnecessary compromises.

An overview of the generic types of building movement such as floor deflection, building sway, differential settlement etc. can be found in various sources such as [5].

Some of the typically most critical modes of building displacement with their effects on the glass enclosure are shown in Figure 5 to Figure 7.

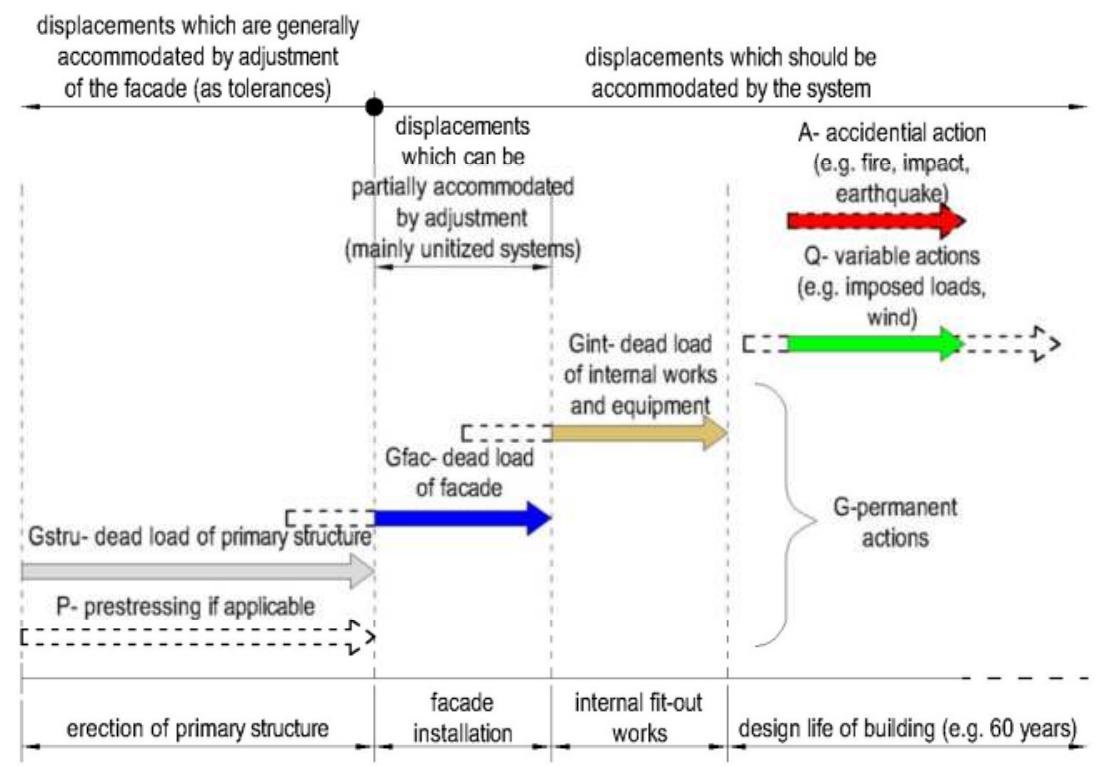

Fig. 4: Stages of application of loads on a building structure. 


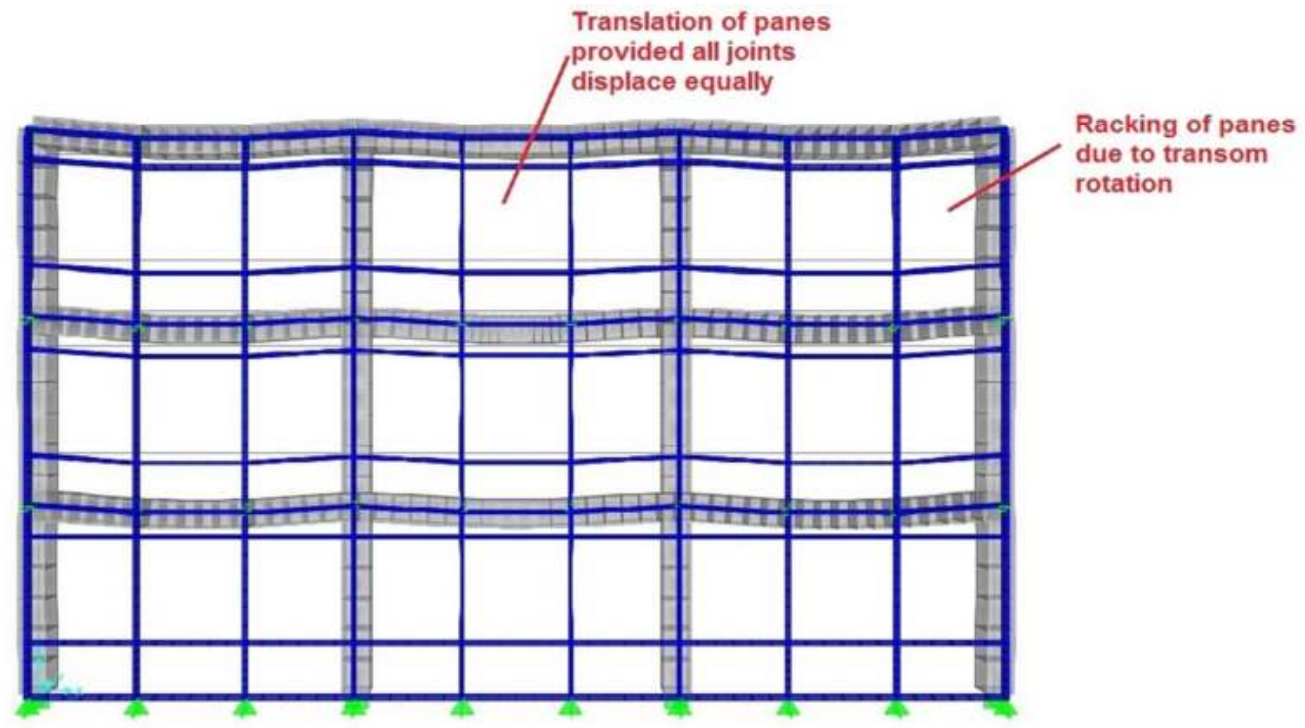

Fig. 5: Typical deformed shape from uniform dead loads and its effect on a stick curtain wall.

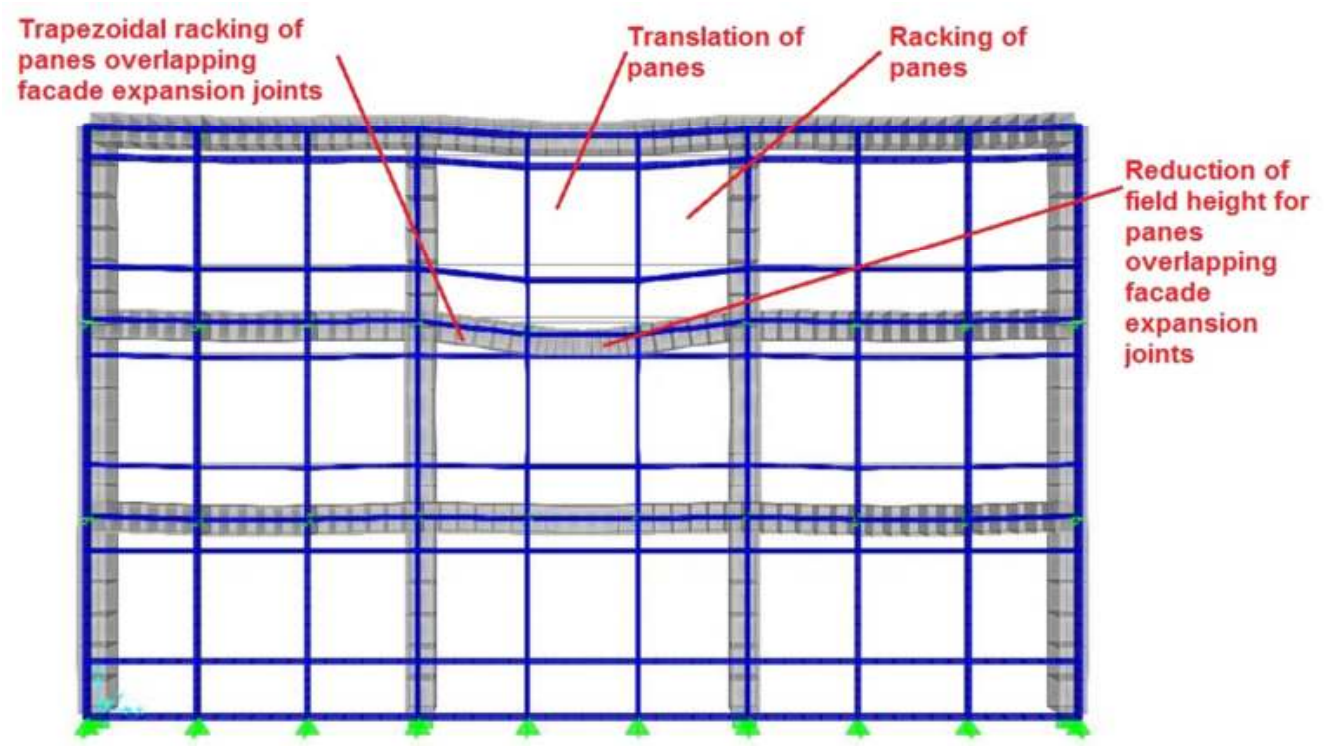

Fig. 6: Typical deformed shape from differential floor deflection (e.g. from imposed load) and its effect on a stick curtain wall.

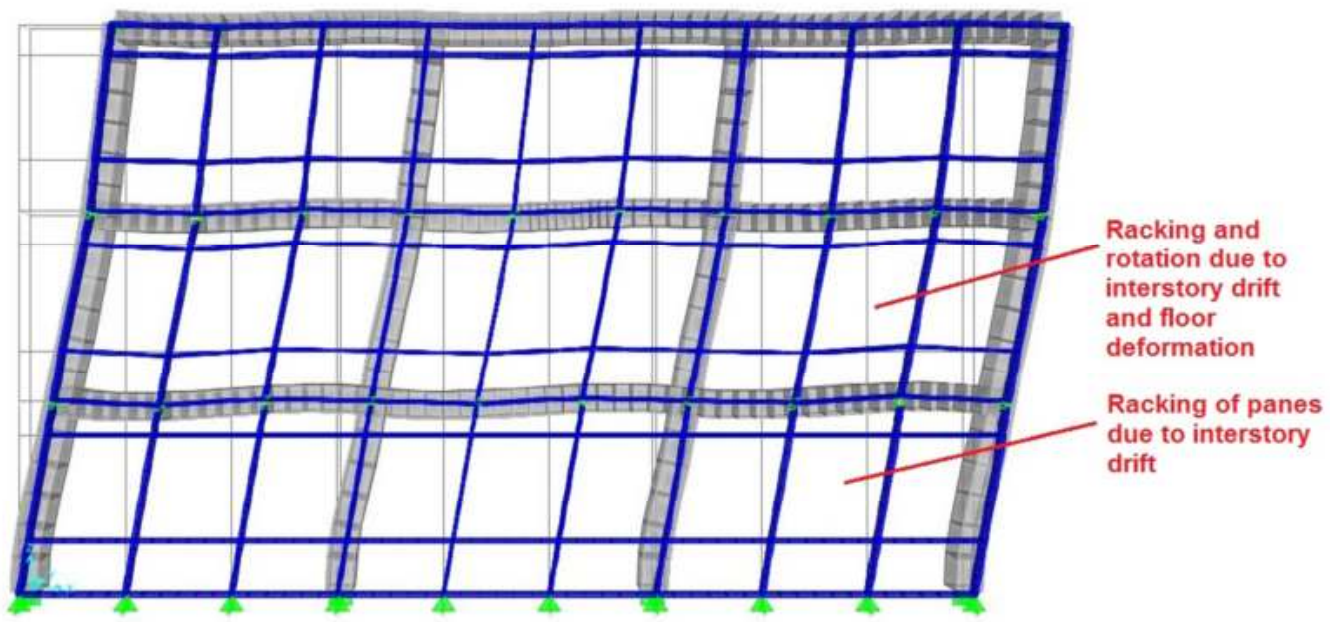

Fig. 7: Typical deformed shape from building sway and its effect on a stick curtain wall. 


\section{MECHANISM OF ACCOMMODATING BUILDING MOVEMENT IN DRY GLAZED SYSTEMS}

\subsection{STICK CURTAIN WALL SYSTEMS}

Stick curtain walls accommodate movement mainly in their edge clearance as glass panes float within the frame after overcoming the friction between glass and gaskets. Failure mechanism is typically edge damage or breakage of glass.
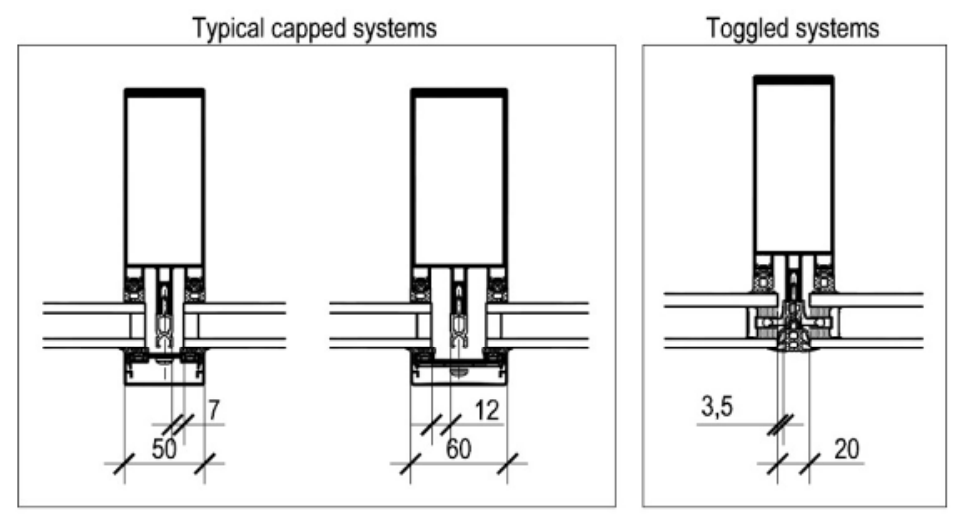

Fig. 8: Typical edge clearances of stick curtain walls, based on (Schüco 2014).

\subsubsection{ACCOMMODATION OF VERTICAL DEFLECTIONS}

Stick facades accommodate vertical movement within the edge clearance with or without rotation of the perimeter frame (Figure 5, Figure 6).

Displacement of the frame without rotation of the pane normally occurs under differential slab deflection if a pane overlaps a mullion expansion joint (expansion joints usually have greater movement capacity), Figure 6 . The ultimate differential displacement of transom ends is given by:

$\Delta_{\text {transom }}=c-t_{c}-f_{\text {transom }}$

Where:

$\Delta_{\text {transom }^{-}} \quad$ Ultimate differential transom displacement;

$c-$ Edge clearance;

$t_{c^{-}} \quad$ Tolerance of the edge clearance size (typically $1,5 \mathrm{~mm}$ for capped systems);

$f_{\text {transom }}{ }^{-} \quad$ Transom deflection under dead load of glass (typically limited to $\min \left(\frac{l}{500} ; 3 \mathrm{~mm}\right)$ ).

Displacement of the frame with rotation of the glass, referred to as "vertical racking", occurs under uniform or differential slab deflections (Figure 5, Figure 6).

After simple transformations of geometrical relations and assuming $\operatorname{tg}\left(\gamma_{v}\right) \approx \gamma_{v}$, rad the ultimate vertical displacement (for the analysed frame) is expressed by the formula:

$\Delta_{v}=\frac{\left(c-t_{c}\right) \cdot b_{\text {frame }}}{\left(h_{\text {frame }}-2 \cdot c\right)} \approx \frac{\left(c-t_{c}\right) \cdot b_{\text {frame }}}{h_{\text {frame }}}$

Increasing the capacity for vertical racking of tall and narrow panes can be accomplished by using side blocks. The ultimate vertical displacement of the transoms becomes $\Delta_{v}=c-t_{c}$. Using side blocks suggests that the glass pane will be subjected to diagonal compression from dead load. Furthermore the capacity for horizontal racking is reduced. 


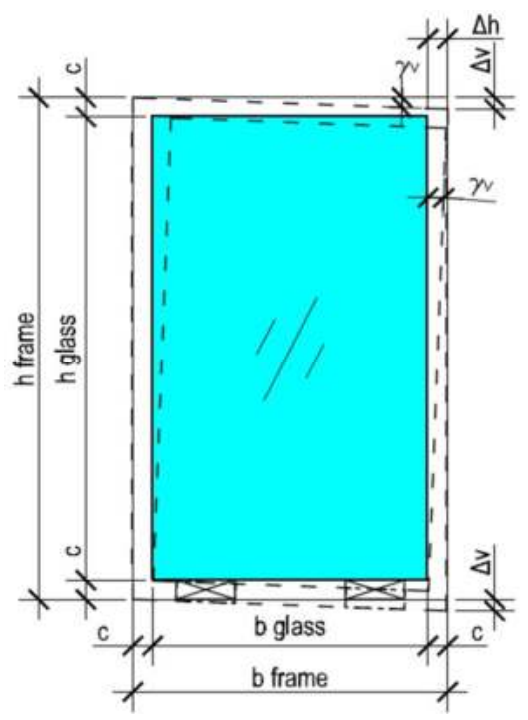

Fig. 9: Vertical racking.

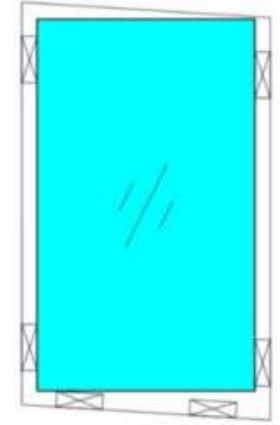

Fig. 10: Modifying the vertical racking capacity using side blocks.

\subsubsection{ACCOMMODATION OF HORIZONTAL DISPLACEMENTS}

The mechanism of accommodating interstorey drifts is presented in the Figure 11, developed on the basis of [10] and [5].

Traditionally in Europe it is accepted that in favour of safety the maximum allowable drift due to wind or seismic sway shall be limited to the first contact of the glass to the frame (Stage 1 in Figure 11). The drift capacity in Stage 1 is $\Delta_{h, I}=c_{s i d e}$, respectively $\Delta_{h, I}=c_{s i d e}-t_{c}$.

After occurrence of glass to frame contact there is an increased risk of glass damage.

Once the edge cover capacity and the friction between glass and glass supports have been overcome the glass pane slides towards the opposite glazing rebate- Stage 2 . The drift capacity of this movement is $\Delta_{h, I I}=c_{\text {side }}$ (without considering tolerances).

After both capacities of the side rebates have been exhausted the pane rotates until the top edge clearance is fully utilized. The drift capacity of this Stage 3 can be obtained as follows:

$\begin{aligned} & \gamma=\frac{\Delta_{h, I I I}}{h_{\text {glass }}} \\ & \gamma=\frac{c_{\text {top }}}{b_{\text {glass }}}\end{aligned} \Rightarrow \Delta_{h, I I I}=\gamma \cdot h_{\text {glass }}=\frac{c_{\text {top }} \cdot h_{\text {glass }}}{b_{\text {glass }}}$

In absence of experimental data, the ultimate total drift capacity of the pane (up to Stage 3 ) is given by: 


$$
\Delta_{h}=\sum_{n=I}^{I I I} \Delta_{h, n}=2 \cdot c_{\text {side }}+\frac{c_{\text {top }} \cdot h_{\text {glass }}}{b_{\text {glass }}}
$$

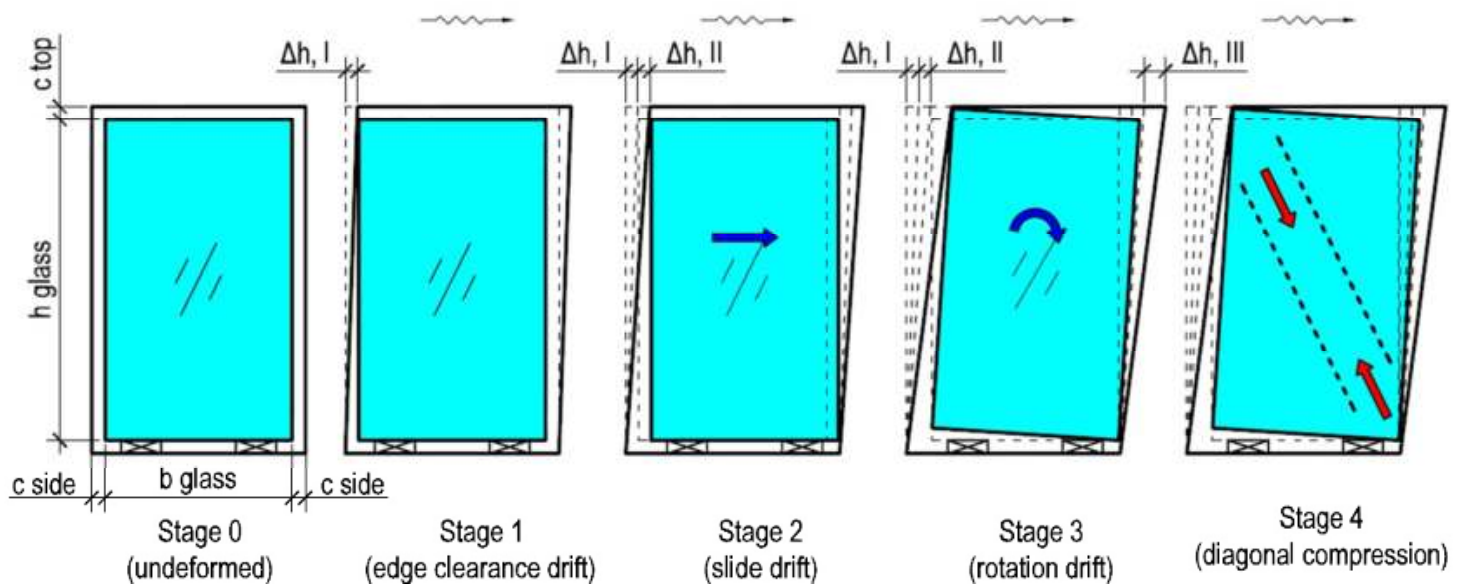

Fig. 11: Mechanism of accommodating horizontal drift.

In Stage 4 the capacity of all available rebates has been exhausted, hence the glass is subjected to diagonal compression to failure.

Use of (Formula 4) could be made for accidental design scenarios (such as earthquake, hurricane). Factors such as tolerances and type and edge quality of the glass have critical influence on the ultimate drift capacities (see Figure 12).
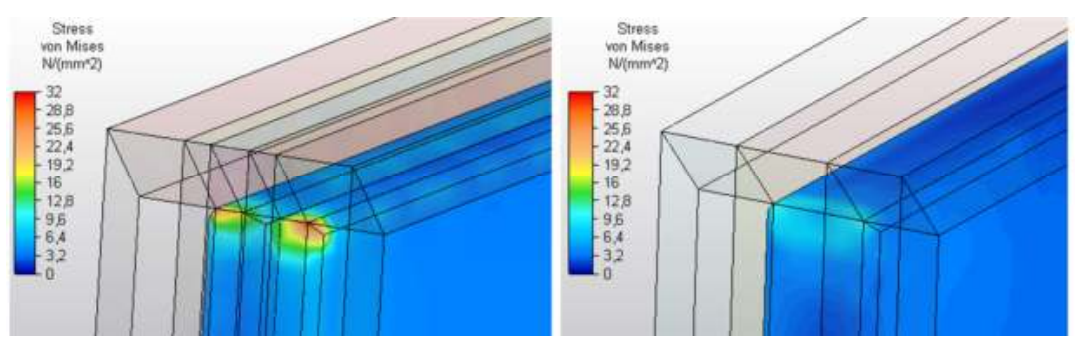

Fig. 12: Local stress levels of identical external load, transferred via frame to glass contact in glass with arrised edges (left) and fine ground edges (right), for guidance.

\subsection{UNITIZED CURTAIN WALL SYSTEMS}

Unlike stick curtain walls unitized curtain wall systems do not typically accommodate building movement in their rebate but in the joints between adjacent units. The joints have certain nominal sizes, respectively minimum and maximum size to provide weather tightness of the envelope (Figure 13). For fundamental modes of building movement such as interstorey drift or slab deflections the unitized panels with spigot connections (typical for Europe) displace as rigid bodies without changing their shape, thus altering the widths of the joints (Figure 14).

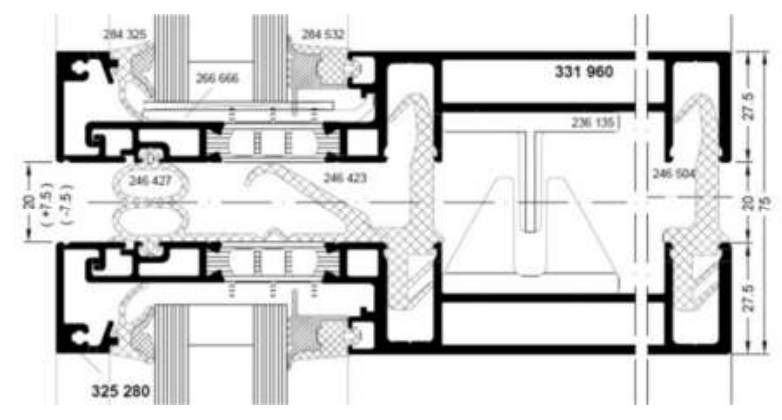

Fig. 13: Typical stack joint, allowing $+/-7,5 \mathrm{~mm}$ alteration of joint width [1]. 
The mechanism of accommodating typical movement modes in unitized systems with or without spigots is explained well in [5].

\subsection{SPECIAL CONSIDERATIONS}

Special considerations need to be taken in order to assess the envelope capacity for complex displacement modes, such as interstory torsion which is very common to contemporary structures. Complex displacement modes often induce additional stress into the envelope members (Figure 14). Those should be taken into consideration in the design of the curtain wall members for the relevant load combination.

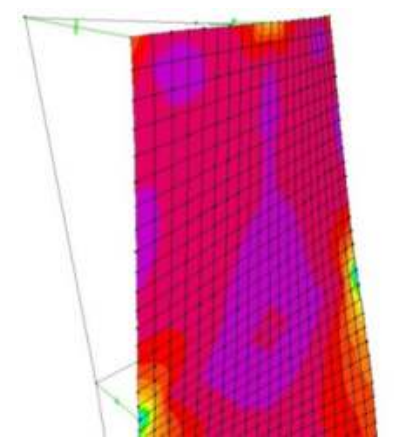

Fig. 14: Additional stress in a glass unit subject to interstory drift.

Combined effects of different movement modes can be critical to the movement analysis. For instance the vertical racking of panes reduces the capacity of the envelope for accommodating interstory drift (Figure 15).

The effects of combined movement should be determined for the most unfavorable characteristic combination of loads with the appropriate $\psi$ factors according to [13] and not by conservatively superposing displacements.

Special considerations should also be taken for earthquake induced building movements. In a seismic event it could be allowed for a certain degree of glass failure [8].

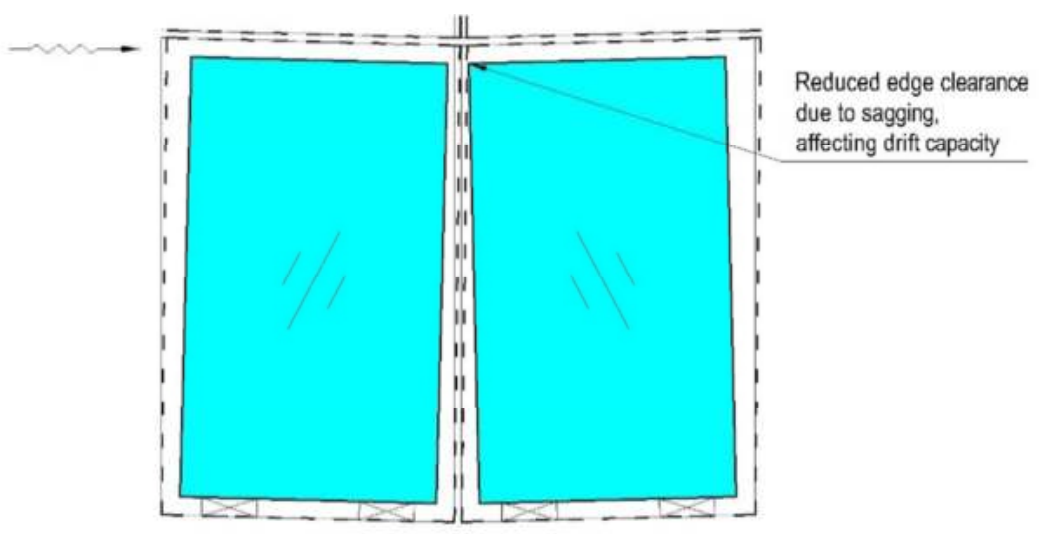

Fig. 15: Effects of combined modes of building movement.

\section{CONCLUSIONS}

It was demonstrated how the displacements of the primary structure can affect the integrity and performance of glazed curtain walls. The existing design methods were discussed with intent for further development and improvement. The presented analysis of the behaviour of curtain walls subject to imposed displacement can be used by practicing designers from all parties. 


\section{Literature}

[1] Schüco, Architekten Informationen und Katalogen., Bielefeld, 2014.

[2] E. C. f. S. (CEN), EN 13830: Curtain walling- Product Standard., Brussels: European Committee for Standardization (CEN), 2003.

[3] F. E. M. A. (FEMA), "FEMA E-74: 6: Seismic Protection of Nonstructural Components.," 2011. [Online]. Available: http://www.fema.gov/plan/prevent/earthquake/fema74/. [Accessed August 2014].

[4] C. f. W. a. C. T. (CWCT), Technical Note No. 55: Movement accommodation in building envelopes., Bath: University of Bath, UK, 2007.

[5] C. f. W. a. C. T. (CWCT), Technical Note No. 56: Accommodation of structural movement., Bath: University of Bath, UK, 2007.

[6] C. f. W. a. C. T. (CWCT), Technical Note No. 57: Cladding movement., Bath: University of Bath, UK, 2007.

[7] A. A. M. A. (AAMA), AAMA 501.4-09: Recommended Static Testing Method for Evaluating Curtain Wall and Storefront Systems Subjected to Seismic and Wind Induced Interstory Drift., 2009.

[8] A. A. M. A. (AAMA), AAMA 501.6-09: Recommended Dynamic Test Method for Determining the Seismic Drift Causing Glass Fallout from a Wall System., 2009.

[9] Behr, Architectural Glass for Earthquake-resistant Buildings., Glass Processing Days, June 2001, 2001.

[10] W. Behr, "Earthquake-Resistant Architectural Glass: New Design Provisions and Test Methods.," 2005. [Online]. Available: http://earthquakeadvisor.com. [Accessed September 2005].

[11] S. a. K. Memari, "Static Finite Element Analysis of Architectural Glass Curtain Walls Under In-Plane Loads and Corresponding Full-Scale Test.," Structural Engineering and Mechanics Journal, 2007.

[12] E. C. f. S. (CEN), EN 1992-1-1: 2005: Eurocode 2: Design of concrete structures- Part 1-1: General rules and rules for buildings., Brussels: European Committee for Standardization (CEN), 2005.

[13] E. C. f. S. (CEN), EN 1990-1-1: 2002: Eurocode 0: Eurocode- Basis of structural design., Brussels: European Committee for Standardization (CEN), 2005. 